\title{
CT Evaluated Sarcopenia Signals: Shorter Survival for Small Cell Lung Cancer Patients
}

\author{
Anna PEKǍ̌OVÁ ${ }^{1,2}$, Matej PEKAR̆ ${ }^{1,3}$, Daniel DANIŠ ${ }^{4}$, Zuzana NOVÁKOVÁ ${ }^{1}$ \\ ${ }^{1}$ Department of Physiology, Faculty of Medicine, Masaryk University, Brno, Czech Republic, \\ ${ }^{2}$ Lung disease Department, Faculty Hospital, Ostrava, Czech Republic, ${ }^{3}$ Department of Surgery, \\ Vitkovice Hospital, Ostrava, Czech Republic, ${ }^{4}$ The Jackson Laboratory for Genomic Medicine, \\ Famington, CT, USA
}

Received April 17, 2021

Accepted October 11, 2021

\section{Summary}

Sarcopenia is an independent risk factor for morbidity and mortality in patients suffering from small cell lung cancer (SCLC), however, a universal indicator of sarcopenia usable in clinical practice is still missing. A novel indicator for describing the severity of cancer could be helpful in tailoring the anti-tumor therapy. The aim of this study was to evaluate the computed tomography (CT) scans of total muscle area and radiation attenuation in patients suffering from small cell lung cancer. We used staging CT scans performed at the time of diagnosis to measure total muscle area (TMA) and average psoas density (PD) at level of the $3^{\text {rd }}$ lumbar vertebra. TMA and PD were statistically evaluated in association with overall survival and disease staging. We used Mann-Whitney test and Spearman's correlation coefficient for statistical testing and p-value under 0.05 was considered statistically significant. Retrospectively we examined 47 patients suffering from SCLC (mean age $65.05 \pm 7.3$ years, BMI $23.97 \pm 4.4 \mathrm{~kg} / \mathrm{m}^{2}$, BSA $1.77 \pm 0.2 \mathrm{~m}^{2}$, 30-day mortality was $4.3 \%$ with 10 months median survival). As sarcopenia was pointed TMA under 55 and $39 \mathrm{~cm}^{2} / \mathrm{m}^{2}$ for men and women respectively. The sarcopenic patients had significantly shorter median survival ( 7 vs. 11 months, $p=0.05$ ). We observed a significant relationship between survival and performance status (Spearman's correlation, $\mathrm{R}=-0.39, \mathrm{p}=0.05$ ). The patients were divided into two groups according to the extensive $(E D, n=34)$ or limited $(L D, n=13)$ form of the disease.

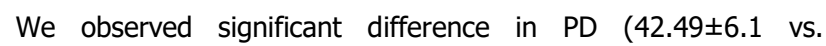
$47.67 \pm 4.5 \mathrm{HU}, \mathrm{p}=0.006$ ) between ED vs. LD groups.

\section{Key words}

Small cell lung cancer • Survival • Sarcopenia • Psoas muscle density • Abdominal muscle area

\section{Corresponding author}

M. Pekař, Zalužanského 15, 70300 Ostrava-Vítkovice, Czech Republic. E-mail: matej.pekar@vtn.agel.cz

\section{Introduction}

Lung cancer is the most common oncological disease in the world. It is a severe disease with interdisciplinary medical overlap and important socioeconomic implications for the patients and the society (Gately 2013). In the Czech Republic it is represented in about $15-20 \%$ by small cell lung cancer (SCLC), that is a very aggressive form of the disease with very poor prognosis, treatment options, and survival periods (Deviany et al. 2021).

Oncologic cachexia, anorexia, phenomena commonly observed in SCLC patients, further decrease the patients' survival by limiting the use of aggressive chemotherapy. In obese SCLC patients, oncologic cachexia might manifest as sarcopenic obesity, where the muscle tissue is infiltrated by fat leading to loss of the muscle strength (Aubrey et al. 2014, Goodpaster et al. 2000). However, presence of sarcopenia is a sign of a poor prognosis regardless of the overall body weight (Martin et al. 2013). Sarcopenia increases the risk of cardiovascular complications, the incidence of postoperative complications, reduces physical performance, impairs the cognitive functions, and weakens healing of acute and chronic diseases (Pekar et al. 2020).

Unlike non-small-cell lung cancer (NSCLC), SCLC is regarded as a multisystem disorder with lack of 
specific therapeutic agents. The surgical treatment is usually only possible at the time of diagnosis, and the first-line treatment of SCLC consists of systemic chemotherapy. However, the high systemic toxicity of the chemotherapy limits its usage, and studies have shown the association of delays and/or interruption of chemotherapy with muscle wasting, resulting in shorter survival periods (Bozzetti 2017, Vega et al. 2016). Therefore, assessment of sarcopenic status at the time of diagnosis has a potential to help with tailoring the chemotherapeutic dose for both NSCLC, a carcinoma where multiple promising therapies emerged recently, and SCLC, where the treatment options remain limited.

Despite many improvements in the field, a universal indicator of sarcopenia available for clinical management of SCLC patients is still missing. Dualenergy X-ray absorptiometry (DXA), the gold standard method for assessment of sarcopenia, is not available widely enough for routine SCLC patients care. However, multiple studies showed a strong correlation between the computed tomography (CT) scans and presence of the postoperative complications, including sarcopenia (Berkel et al. 2018, Jones et al. 2015, Martin et al. 2013). Specifically, the single slice measurements in lumbar vertebra levels seem to have strong predictive value in the evaluation of sarcopenic status. Total abdominal muscle area and the radiation attenuation measured in Hounsfield units (HU) at the specific lumbar vertebra landmarks correlate with the body composition approximates provided by DXA (Mourtzakis et al. 2008). There is a pressing need for reliable method for assessing sarcopenic status, as it could be used as an informative factor for tailoring anti-tumor therapy to SCLC patients.

The aim of our study was to evaluate CT scans of total muscle area and radiation attenuation in patients suffering from SCLC as a predictive factor of their survival.

\section{Methods}

\section{Patient cohort}

We retrospectively identified patients with the diagnosis of SCLC confirmed by histology who were treated at the Department of Lung disease of Vitkovice Hospital, Ostrava, Czech Republic in the years 2010-2016. The study was approved by The Multicentric Ethics Committee of Vitkovice Hospital, in accordance with the ethical standards of the Helsinki Declaration (EK/224/2019). We evaluated patients' medical history, including the $\mathrm{CT}$ documentation, BMI, the performance status (ECOG), TMA, and PD. The next analysis was later performed separately for patients suffering from the extensive (ED) and limited (LD) form of the disease.

\section{Performance status}

The ECOG Scale of Performance Status was used to evaluate a patient's level of functioning in terms of their ability to care for themselves, daily activity, and physical ability (Table 1) (Oken et al. 1982).

Table 1. ECOG Performance Status.

\begin{tabular}{ll}
\hline Grade & ECOG \\
\hline 0 & $\begin{array}{l}\text { Fully active, able to carry on all pre-disease performance without restriction. } \\
\text { Restricted in physically strenuous activity but ambulatory and able to carry out work of a light or sedentary } \\
\text { nature, e.g. light house work, office work. }\end{array}$ \\
& $\begin{array}{l}\text { Ambulatory and capable of all self-care but unable to carry out any work activities. Up and about more than } \\
50 \% \text { of waking hours. }\end{array}$ \\
3 & $\begin{array}{l}\text { Capable of only limited self-care, confined to bed or chair more than } 50 \% \text { of waking hours. } \\
4\end{array}$ \\
5 & Completely disabled. Cannot carry on any self-care. Totally confined to bed or chair.
\end{tabular}

ECOG - the Eastern Cooperative Oncology Group (Oken et al. 1982).

\section{Limited and extensive form of SCLC}

SCLC is described as limited if the cancer is contained in a single area on one side of the chest, with or without ipsilateral mediastinal or supraclavicular lymph nodes, with or without malignant pleural effusion that can be treated with radiotherapy to just one area. Extensive disease does not meet the criteria of the limited one. 


\section{The analysis of CT scans}

CT muscle mass and density were measured by a single operator skilled in radiologic anatomy. To analyze the body composition, we used cross sections at the level of the third lumbar vertebra where both transverse processes were visible (Fig. 1). We performed the scans according to the same radiation protocol in every patient. We defined the thickness of the CT scan single slice to $5 \mathrm{~mm}$. The muscles included into the analysis were psoas, quadratus lumborum, erector spinae, the external and internal obliques, transversus abdominis and rectus abdominis muscles. The total abdominal muscle area (TMA) and the average psoas density (PD) were measured semi-automatically using the IntelliSpace Portal 9.0 software (Phillips).

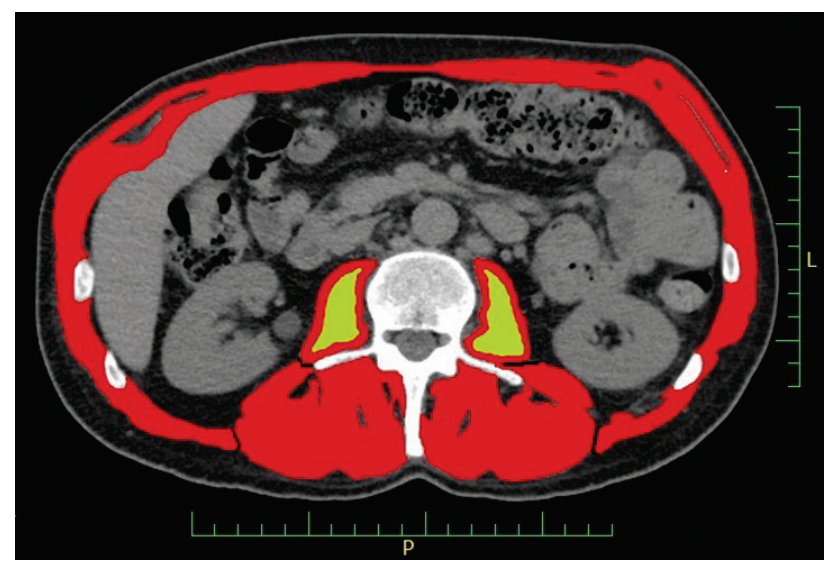

Fig. 1. $C T$ scan at the $3^{\text {rd }}$ lumbar vertebra. Total muscle area (TMA) - red color, Psoas density (PD) - lime color (shows the area for automatic calculating of density), Ribs and $L 3$ vertebra white color.

\section{Definition of sarcopenia}

As sarcopenia was pointed TMA under 55 and $39 \mathrm{~cm}^{2} / \mathrm{m}^{2}$ for men and women respectively. Cut-off values were used as proposed by international consensus for cancer cachexia (Fearon et al. 2011).

\section{Statistical analysis}

We used the non-parametric Mann-Whitney U-test and Spearman's correlation coefficient to detect differences between the CT scans, and $\mathrm{p}<0.05$ was considered as statistically significant (Statistica 12, StatSoft, CZ).

\section{Results}

We retrospectively identified 47 patients with histologically proved SCLC (25 women and 22 men, for basic characteristic see Table 2).
Table 2. Summary of the SCLC patient cohort.

\begin{tabular}{|c|c|c|c|c|c|c|}
\hline \multirow{2}{*}{47 patients } & \multicolumn{3}{|c|}{ Women } & \multicolumn{3}{|c|}{ Men } \\
\hline & \multicolumn{3}{|c|}{25} & \multicolumn{3}{|c|}{22} \\
\hline Age & \multicolumn{6}{|c|}{$65.05 \pm 7.3$ years } \\
\hline$B M I$ & \multicolumn{6}{|c|}{$23.97 \pm 4.4 \mathrm{~kg} / \mathrm{m}^{2}$} \\
\hline$B S A$ & \multicolumn{6}{|c|}{$1.77 \pm 0.2 \mathrm{~m}^{2}$} \\
\hline $\begin{array}{l}\text { Median } \\
\text { survival }\end{array}$ & \multicolumn{6}{|c|}{10 months } \\
\hline \multirow{5}{*}{ Stage } & \multicolumn{6}{|c|}{ TNM classification ( $7^{\text {th }}$ edition) } \\
\hline & $\mathbf{0}$ & I A, B & II A,B & IIIA & & IV \\
\hline & 0 & 0 & 1 & 15 & & 31 \\
\hline & \multicolumn{3}{|c|}{ Limited disease } & \multicolumn{3}{|c|}{13} \\
\hline & \multicolumn{3}{|c|}{ Extensive disease } & \multicolumn{3}{|c|}{34} \\
\hline \multirow{2}{*}{$\begin{array}{l}\text { ECOG } \\
\text { Performance } \\
\text { Status } \\
\end{array}$} & $\mathbf{0}$ & 1 & 2 & 3 & & 4 \\
\hline & 1 & 31 & 7 & 7 & & 1 \\
\hline \multirow{2}{*}{$\begin{array}{l}\text { Cigarette } \\
\text { abuse }\end{array}$} & \multicolumn{2}{|c|}{ Smoker } & \multicolumn{2}{|c|}{ Ex-smoker } & \multicolumn{2}{|c|}{ Non-smoker } \\
\hline & \multicolumn{2}{|c|}{26} & \multicolumn{2}{|c|}{20} & & 1 \\
\hline Comorbidities & \multicolumn{6}{|c|}{$\begin{array}{l}\text { Chronic kidney disease }-1 \\
\quad \text { Dyslipidemia }-10 \\
\text { Cardiovascular disease }-10 \\
\text { Oncological duplicity }-8\end{array}$} \\
\hline
\end{tabular}

After evaluating CT documentation and ascertaining the mean PD and TMA, we split the patients into two groups according to their sarcopenic status. We evaluated the survival, and we observed significantly shorter median survival in the group of sarcopenic patients ( 7 vs. 11 months, $\mathrm{p}=0.05$, Fig. $2 \mathrm{~A}$ ).

Significant relationship was observed between survival and performance status (Spearman's correlation, $\mathrm{R}=-0.39, \mathrm{p}=0.05$, Fig. 2B).

The patients were divided into two groups according to the extensive (ED, $n=34$ patients) or limited ( $\mathrm{LD}, \mathrm{n}=13$ patients) form of the disease. We observed significant difference in PD $(42.49 \pm 6.1$ vs. 47.67 $\pm 4.5 \mathrm{HU}, \mathrm{p}=0.006$ ) between $\mathrm{ED}$ vs. LD groups (Fig. 2C). 

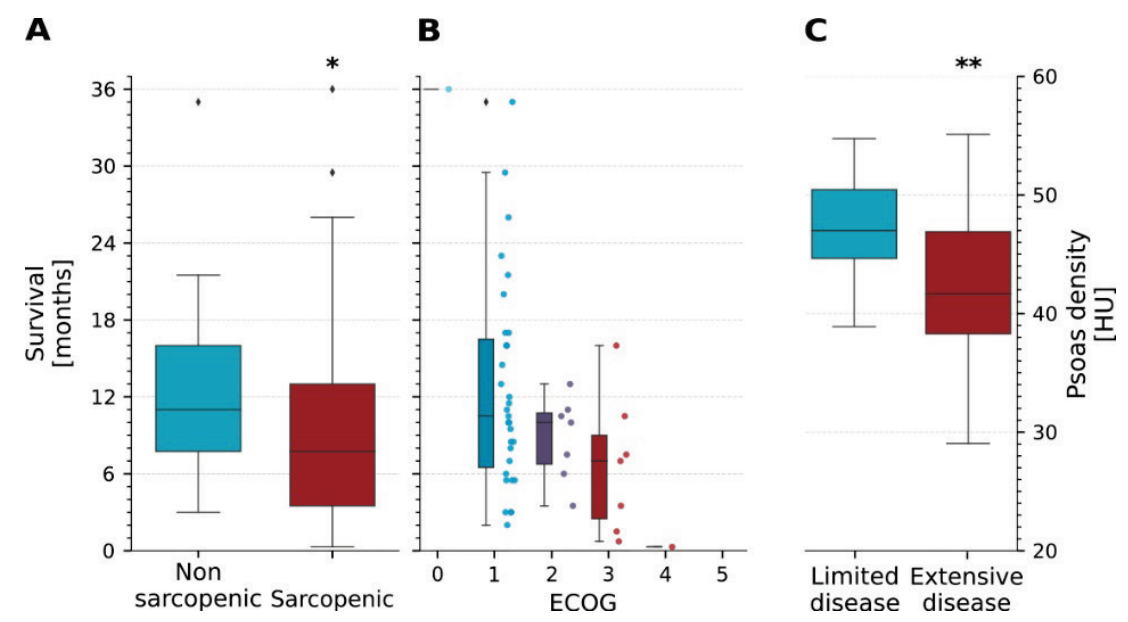

Fig. 2. Survival and psoas density of the patients evaluated in this study. * Mann-Whitney test, $\quad \mathrm{p}<0.05$, ** Mann-Whitney test, $\mathrm{p}<0.01$. (A) Box plot representing survival of sarcopenic and non-sarcopenic patients. The horizontal line of each box indicates the median survival, box borders indicate positions of the $1^{\text {st }}$ and the $3^{\text {rd }}$ quartile, and the whiskers indicate $1.5 \times$ the interquartile range. (B) Comparison of patient survival depending on ECOG performance class. We present box plots as well as the individual survivals. (C) Box plot depicting psoas density measured in patients with limited $(n=13)$ or extensive $(n=34)$ stage.

\section{Discussion}

Measured muscle area below the physiological values in patients is a sign of sarcopenia or cachexia that is the image of poor nutritient and physical performance status of the patients (Bučar Pajek and Pajek 2018). Both conditions lead to worsening of anastomosis and wounds healing, raise the probability of postoperative complications and decreased survival in cancer patients (Gaillard et al. 2018, Jones et al. 2015, Zhang et al. 2018). Sarcopenia is associated primarily with high age (Baumgartner 2000, Zadák 2016), low level of physical activity, heritability, and other possible confounders (Sayer et al. 2008).

The studies show, that some sarcopenic indicators can be effective predictors of mortality in cancer patients. Sarcopenic patients do not tolerate aggressive chemotherapy, leading to prolongation or interruption of the chemotherapeutic cycles (Bozzetti 2017, Vega et al. 2016). The precise cause of the higher toxicity is not yet known. One possible reason is that the calculation of the chemotherapeutic dose does not consider features of body composition. The calculation usually includes body height, weight, selected laboratory parameters, and BSA in obese SCLC patients. However, the calculation that includes features of body composition, such as skeletal muscle mass, has a potential to provide a dose the patient can tolerate better. It is, therefore, imperative to find informative indicators of sarcopenia that are available in the clinical practice.

Skeletal muscle radiation attenuation measured from CT scans indicates the ectopic lipid deposits in muscles, that impair its functionality and are visually not identified as fat in CT image (Berkel et al. 2018, Engelke et al. 2018). Increasing the phantom's lipid concentration by $1 \mathrm{~g} / 100 \mathrm{ml}$ decreased its attenuation by $1 \mathrm{HU}$ (Berkel et al. 2018). This statement observed in obese population is defined as sarcopenic obesity. However the radiation attenuation could be observed as well in non-obese patients, who are in high risk of postoperative complications (Van Dijk et al. 2017).

There are two different approaches to the evaluation of body composition: DXA measurement and CT scans. Both of them have their advantages and disadvantages, as well (Mourtzakis et al. 2008). DXA is more complex, it has smaller dose of radiation, it scans the whole body, and it is a cheap and fast examination, however it is not a part of standard staging examination. CT scans on the other hand, are more detailed and depict the muscle structure. They are available in daily hospital practice and diagnostic staging CTs are routinely performed in the time of cancer diagnosis onset, so $\mathrm{CT}$ images for future analysis are available with no extra costs.

A typical imagining technique in cancer cachexia is the analysis of a single CT scan at the level of L3. The trunk muscle area at the L4-5 level or $5 \mathrm{~cm}$ above is highly correlated with the total body skeletal muscle volume (Engelke et al. 2018). However, CT scans measurements depend on the quality of software and greatly depend on the skills of a person, who provides the manual part of images' assessment. Generally in various studies this is limited by the evaluations by a single operator. Furthermore, the evaluation procedure takes approximately $10 \mathrm{~min}$ per one patient. Nowadays some fully automated software was developed (Paris et al. 2020).

Presence of sarcopenia was associated with poor 
prognosis in SCLC patients. Therefore, the importance of patients' risk stratification is obvious. Hence, we consider important further exploration and implementation of new technologies and investigations that can serve to identify patients in risk. We consider introducing another CT scan scoring system as a simple tool for predicting the risk in patients and thus stratifying risk groups of patients who require a more proactive approach. The more we know about patients' personal claims, the more we are able to tailor their therapy, point to nutrition and physical recovery and to prepare them for chemotherapy administration.

TMA reflects muscle quantity rather than its quality. The novel definition of sarcopenia is based on both - the loss of volume and strength of muscles. Another sarcopenia indicator PD contains more information about the muscle quality, because the radiation attenuation indicates the lipid deposits in muscles that impair its function not affecting its volume. Therefore TMA in combination with PD might be the ideal sarcopenic indicators for daily practice.

The true value of TMA and PD - the new sarcopenic indicators - as predictors for cancer mortality has to be identified in future studies. Further studies should be provided as well to eliminate the statistical error due to limited sample size and one center characteristic of our results.

\section{Conclusions}

Our study shows that patients suffering both from SCLC and sarcopenia according to TMA have significantly shorter survival. Moreover, the patients with extensive form of SCLC have significantly lower PD. Because of the simplicity of collecting and evaluating these data (TMA and PD) from staging CT scan, we recommend to use CT scan for assessment of sarcopenic status of patients within the routine clinical practice.

\section{Conflict of Interest}

There is no conflict of interest.

\section{Acknowledgements}

This study was supported by Specific University Research Grant no. MUNI/A/1246/2020 provided by the Ministry of Education, Youth, and Sports of the Czech Republic. The authors wish to acknowledge the contribution of Mr. Jaroslav Krátký, MD, the head of Radiology Department, Vitkovice Hospital, Ostrava, Czech Republic for his help with CT scans' management.

\section{References}

AUBREY J, ESFANDIARI N, BARACOS VE, BUTEAU FA, FRENETTE J, PUTMAN CT, MAZURAK VC: Measurement of skeletal muscle radiation attenuation and basis of its biological variation. Acta Physiol Oxf Engl 210: 489-497, 2014. https://doi.org/10.1111/apha.12224

BAUMGARTNER RN: Body composition in healthy aging. Ann N Y Acad Sci 904: 437, 2000. https://doi.org/10.1111/j.1749-6632.2000.tb06498.x

BERKEL AEM, KLAASE JM, DE GRAAFF F, BRUSSE-KEIZER MGJ, BONGERS BC, VAN MEETEREN NLU: Patient's skeletal muscle radiation attenuation and sarcopenic obesity are associated with postoperative morbidity after neoadjuvant chemoradiation and resection for rectal cancer. Dig Surg 36: 376-383, 2018. https://doi.org/10.1159/000490069

BOZZETTI F: Forcing the vicious circle: sarcopenia increases toxicity, decreases response to chemotherapy and worsens with chemotherapy. Ann Oncol 28: 2107-2118, 2017. https://doi.org/10.1093/annonc/mdx271

BUČAR PAJEK M, PAJEK J: Characterization of deficits across the spectrum of motor abilities in dialysis patients and the impact of sarcopenic overweight and obesity. Clin Nutr 37: 870-877, 2018. https://doi.org/10.1016/j.clnu.2017.03.008

DEVIANY PE, GANTI AK, ISLAM KMM: Factors associated with treatment refusal and impact of treatment refusal on survival of patients with small cell lung cancer. Oncology (Williston Park) 35: 111-118, 2021. https://doi.org/10.46883/ONC.2021.3503.0111

ENGELKE K, MUSEYKO O, WANG L, LAREDO JD: Quantitative analysis of skeletal muscle by computed tomography imaging-state of the art. J Orthop Transl 15: 91-103, 2018. https://doi.org/10.1016/j.jot.2018.10.004 
FEARON K, STRASSER F, ANKER SD, BOSAEUS I, BRUERA E, FAINSINGER RL, JATOI A, LOPRINZI CH, MACDONALD N, MANTOVANI G, DAVIS M, MUSCARITOLI M, OTTERY F, RADBRUCH L, RAVASCO P, WALSH D, WILCOCK A, KAASA S, BARACOS VE: Definition and classification of cancer cachexia: An international consensus. Lancet Oncol 12: 489-495, 2011. https://doi.org/10.1016/S14702045(10)70218-7

GAILLARD M, TRANCHART H, MAITRE S, PERLEMUTER G, LAINAS P, DAGHER I: Preoperative detection of sarcopenic obesity helps to predict the occurrence of gastric leak after sleeve gastrectomy. Obes Surg 28: 2379-2385, 2018. https://doi.org/10.1007/s11695-018-3169-0

GATELY K: Lung Cancer: A Comprehensive Overview. New York: Nova Science Publishers, Inc (Cancer Etiology, Diagnosis and Treatments), 2013, $309 \mathrm{p}$.

GOODPASTER BH, KELLEY DE, THAETE FL, HE J, ROSS R: Skeletal muscle attenuation determined by computed tomography is associated with skeletal muscle lipid content. J Appl Physiol (1985) 89: 104-110, 2000. https://doi.org/10.1152/jappl.2000.89.1.104

JONES KI, DOLEMAN B, SCOTT S, LUND JN, WILLIAMS JP: Simple psoas cross-sectional area measurement is a quick and easy method to assess sarcopenia and predicts major surgical complications. Colorectal Dis 17: O20-O26, 2015. https://doi.org/10.1111/codi.12805

MARTIN L, BIRDSELL L, MACDONALD N, REIMAN T, CLANDININ MT, MCCARGAR LJ, MURPHY R, GHOSH S, SAWYER MB, BARACOS VE: Cancer cachexia in the age of obesity: skeletal muscle depletion is a powerful prognostic factor, independent of body mass index. J Clin Oncol 31: 1539-1547, 2013. https://doi.org/10.1200/JCO.2012.45.2722

MOURTZAKIS M, PRADO CMM, LIEFFERS JR, REIMAN T, MCCARGAR LJ, BARACOS VE: A practical and precise approach to quantification of body composition in cancer patients using computed tomography images acquired during routine care. Appl Physiol Nutr Metab 33: 997-1006, 2008. https://doi.org/10.1139/H08-075

OKEN MM, CREECH RH, TORMEY DC, HORTON J, DAVIS TE, MCFADDEN ET, CARBONE PP: Toxicity and response criteria of the Eastern Cooperative Oncology Group. Am J Clin Oncol 5: 649-655, 1982. https://doi.org/10.1097/00000421-198212000-00014

PARIS MT, TANDON P, HEYLAND DK, FURBERG H, PREMJI T, LOW G, MOURTZAKIS M: Automated body composition analysis of clinically acquired computed tomography scans using neural networks. Clin Nutr 39: 3049-3055, 2020. https://doi.org/10.1016/j.clnu.2020.01.008

PEKAR M, PEKAROVA A, CHOVANCOVA T, HOLECZY P: Sarcopenic obesity - current view. (Article in Czech) Vnitr Lek 66: 39-43, 2020. https://doi.org/10.36290/vnl.2020.007

SAYER A, SYDDALL H, MARTIN H, PATEL H, BAYLIS D, COOPER C: The developmental origins of sarcopenia. J Nutr Health Aging 12: 427-432, 2008. https://doi.org/10.1007/BF02982703

VAN DIJK DPJ, BAKENS MJAM, COOLSEN MME, RENSEN SS, VAN DAM RM, BOURS MJL, WEIJENBERG MP, DEJONG CHC, DAMINK SWMO: Low skeletal muscle radiation attenuation and visceral adiposity are associated with overall survival and surgical site infections in patients with pancreatic cancer. J Cachexia Sarcopenia Muscle 8: 317-326, 2017. https://doi.org/10.1002/jcsm.12155

VEGA MCMD, LAVIANO A, PIMENTEL GD: Sarcopenia and chemotherapy-mediated toxicity. Einstein 14: 580-584, 2016. https://doi.org/10.1590/s1679-45082016md3740

ZADÁK Z: Prevention and therapy of sarcopenia in the ageing. (Article in Czech) Vnitr Lek 62: 671-677, 2016.

ZHANG WT, LIN J, CHEN WS, HUANG YS, WU RS, CHEN XD, LOU N, CHI CH, HU CY, SHEN X: Sarcopenic obesity is associated with severe postoperative complications in gastric cancer patients undergoing gastrectomy: a prospective study. J Gastrointest Surg 22: 1861-1869, 2018. https://doi.org/10.1007/s11605$\underline{018-3835-5}$ 